\title{
LOS DERECHOS DE LA NATURALEZA EN LOS TRIBUNALES ECUATORIANOS ${ }^{\mathrm{I}}$ Nature's Rights in Ecuadorian Courts
}

\author{
María José Narváez ÁlvareZ \\ JHOel Escudero Soliz ${ }^{3}$ \\ Instituto de Altos Estudios Nacionales (IAEN), Quito, Ecuador
}

\section{Resumen}

El reconocimiento de los derechos de la Naturaleza ha suscitado todo tipo de reacciones en el mundo jurídico, sea a favor o en contra de estos, lo que es esperable con una innovación de tal magnitud, que afecta a la raíz antropocéntrica con la cual se crea y funciona el derecho. Más allá de las propuestas teóricas que se revisan a modo de marco conceptual en el presente estudio, nos proponemos analizar los derechos de la Naturaleza como una práctica judicial, en donde nos encontramos con una constante confusión que se desprende de la aparente relación entre el derecho ambiental y los derechos de la Naturaleza, lo que causa la pérdida de la esencia o vocación de estos últimos, que son de matriz biocéntrica y ecocéntrica. Para demostrar esta afirmación, se realizó el estudio del caso denominado Manglar Mataje Cayapas resuelto por la Corte Constitucional del Ecuador, tomando en cuenta las siguientes variables: relevancia del caso, sujeto de protección, el todo de la Naturaleza y el bien jurídico protegido del derecho ambiental, elementos que son tratados de forma unívoca y no diferencial por los jueces para decidir los casos de los derechos de la Naturaleza, lo que permite sostener que a los tomadores de la decisión judicial no les es posible salir de la matriz basada en el ser humano, la propiedad y el ambiente. Finalmente, en su conjunto el artículo busca despejar las confusiones y contribuye con criterios para que estos casos se decidan desde y para la Naturaleza.

\section{Palabras clave}

Derechos de la Naturaleza, antropocentrismo, biocentrismo, ecocentrismo, derechos ambientales, juez constitucional.

\footnotetext{
Abstract

The recognition of the Nature's rights has stirred up all kinds of reactions in the legal world, whether it be for or against them, which is expected with such an innovative concept, which affects the anthropocentric root with which the law is created and functions. Beyond the theoretical proposals that are reviewed as the conceptual framework of this study, we intend to analyze the rights of nature as a judicial practice, where we find a constant confusion that follows from the apparent relationship between environmental law and the rights of nature, which cause the loss of the essence or vocation of the latter, which are biocentric and ecocentric. To demonstrate this assertion, the study of the case called Manglar Mataje

${ }^{1}$ Los/las autores/as de este artículo han contribuido en partes iguales.

${ }^{2}$ Abogada, Magíster en Derecho Administrativo, Candidata a Doctora por la Universidad Andina Simón Bolívar Sede Ecuador, Docente a tiempo completo del Instituto de Altos Estudios Nacionales (IAEN), Ecuador. Correo electrónico: maria.narvaez@iaen.edu.ec; ORCID: https://orcid.org/0000-0003-0016-2870.

${ }^{3}$ Doctor en Derecho por la Universidad Andina Simón Bolívar Sede Ecuador, Vicerrector del Instituto de Altos Estudios Nacionales (IAEN), Ecuador. Correo electrónico: jhoel.escudero@iaen.edu.ec; ORCID: https://orcid.org/0000-0002-4776-6615.
} 
Cayapas resolved by the Constitutional Court of Ecuador was carried out, taking into account the following variables: relevance of the case, subject of protection, the whole of nature and the legal asset protected from environmental law, elements that are univocally and non-differentially stated by the judges who decide the cases of the rights of nature, which upholds the argument that it is not possible for the makers of the judicial decision to leave the matrix based on the human being, the property and the environment. Finally, as a whole, the article seeks to clear up the confusion and contribute with criteria so that these cases are decided from and for nature.

\section{Key words}

Nature Rights, Anthropocentrism, Biocentrism, Ecocentrism, Environmental Rights, Constitutional Judge.

\section{Introducción}

El reconocimiento de la Naturaleza como sujeto de derechos en la Carta Magna ecuatoriana aún no está libre de críticas. Inicialmente, en el escenario político se hicieron ataques y ridiculizaciones con exageraciones sobre el tema; lo propio ocurrió en la esfera jurídica, se calculaba lo improbable de sus contenidos y de los mecanismos de protección, usando sofismas y preguntas falaces que buscaban demostrar lo imposible: ¿acaso una planta será capaz de plantear una demanda?; ¿podrá el manglar o la selva caber en un tribunal?; ¿será posible que la cucaracha blanca se defienda de su inevitable extinción? Cuestionamientos estos que por varios años desde la expedición de la Constitución mantuvieron a la Naturaleza en un espacio utópico e irrealizable, esperando que llegue un caso o juicio para solicitar su tutela. Sin embargo, como ocurre con todos los nuevos derechos, es probable que generen antagonismo y conflicto, a menos que se ignoren por completo.

Existen filósofos, políticos y juristas que creen posible que los derechos de la Naturaleza sean protegibles, porque el concepto de desarrollo sostenible que traía la promesa de superar la crisis ambiental, se ha visto envuelto en un pantano de confusión y desacuerdos que requiere volver a conceptualizar los sistemas de gobierno humano, que descosifiquen a la Naturaleza, asumiendo los paradigmas biocéntricos y ecocéntricos, que cuestionen al sistema hegemónico, a los "otros", y los valores del todo, sus métodos, sus análisis, que por inveterada costumbre están arraigados hasta en el inconsciente de las personas (Sagot, 2020).

La perspectiva de que los humanos son uno más de los componentes de un sistema natural amplio, que regenta cómo funciona la Tierra en su conjunto (y, en última instancia, el universo mismo) (Cullinan, 2019), torna al Derecho Ambiental en insuficiente para la tutela de la Naturaleza como sujeto con derechos propios y autónomos, que no depende del ser humano, como proclaman todos los derechos hasta ahora reconocidos.

En el caso de Ecuador, sorprende que en 12 años de vigencia de la Constitución y reconocimiento de esos derechos, no se haya creado jurisprudencia suficiente sobre la Naturaleza como sujeto de derechos, razón por la que en este artículo se procura evidenciar las diferencias entre el derecho humano a un ambiente sano (enfoque antropocéntrico) y los derechos de la Naturaleza (enfoque biocéntrico y ecocéntrico), y como trasciende esta distinción en los litigios en los cuales la Naturaleza es parte procesal. Para ello, se analiza la sentencia No. 166-15-SEP-CC dictada en el caso No. 507-12-EP, denominado Manglar Cayapas Mataje en contra de la Camaronera Marmeza para efectos del presente estudio, a cuyos argumentos jurisprudenciales se confrontarán con el marco teórico propuesto, para 
clarificar las diferencias entre derechos de la Naturaleza y el derecho humano a vivir en un ambiente sano.

A criterio de los investigadores, este caso tiene particular relevancia porque logró una decisum favorable para los derechos de la Naturaleza. No obstante, el razonamiento de la Corte Constitucional, incurrió en el yerro de abordar los derechos de la Naturaleza desde las estructuras e instituciones propias del conservacionismo antropocéntrico del Derecho Ambiental.

\section{La diferencia entre los bienes jurídicos ambientales y los derechos de la Naturaleza}

Frente a la existencia de la crisis ambiental, en un contexto de desarrollo que trajo consigo una deuda ecológica inconmensurable (Leff, 2002, p. 35), hacia la década de 1970 surgió la necesidad de transformar el orden legal e institucional para dotar de protección jurídica al ambiente a través del Derecho Ambiental, que se distingue de otras ramas del Derecho, particularmente del Derecho Civil, en cuanto a sus principios rectores y el objeto jurídico que regula.

Mientras el Derecho Civil tutela jurídicamente los elementos base del ambiente, de forma singularizada, y en medida que tengan un titular propietario, el Derecho Ambiental se encamina a proteger los bienes que desempeñan una función ambiental respecto de los otros con los que interactúan (González, 2003, pp. 14 - 15); mientras el Derecho Civil es eminentemente reparador, el Derecho Ambiental es eminentemente preventivo y excepcionalmente reparador.

No obstante, el Derecho Ambiental emerge marcado por la herencia antropocéntrica que concibe al ambiente como un objeto que se puede fragmentar en componentes, que bien pueden insertarse a los procesos de producción como 'recursos' apropiables, y al ser humano como "un ser superior y dominador de todo lo que es natural, siendo que el ambiente es reducido a un simple reservorio de recursos, antes de convertirse en un depósito de residuos" (Morato y Franca, 2019, p. 98). ${ }^{4}$

Frente a la ineficacia del Derecho Ambiental para detener el deterioro ambiental, y la habilidad del conocimiento humano y la tecnología para producir más, pero también para contaminar más, aparecen los enfoques biocéntrico y ecocéntrico.

El biocentrismo, que deja de ver al hombre como el único dueño de la Naturaleza para otorgarles a ambos el mismo respeto, teniendo presente que si no se conserva la Naturaleza no podrá preservarse el ser humano; y, [...] el ecocentrismo, desde el cual el hombre no es dueño de la Naturaleza sino que por el contrario, es él quien hace parte de la misma por la larga cadena evolutiva, lo que consecuentemente lleva a que se reconozca que la Naturaleza es en sí misma un sujeto de derechos que tiene que ser protegido y ejercidos por medio de representante legal para materializar este reconocimiento. (Rodríguez y VargasChávez, 2019, p. 240).

El biocentrismo aboga por la protección de los elementos y recursos naturales en tanto sus funciones ambientales garantizan la continuidad de la trama de la vida en cualquiera de sus manifestaciones, como atributo del planeta, mientras que, el ecocentrismo da cuenta del valor intrínseco de los procesos ecológicos dinámicos, los ecosistemas y de sus componentes por igual, que configuran el equilibrio ecológico planetario y que en conjunto forman una "universalidad".

\footnotetext{
${ }^{4}$ El día 13 de abril de 2021, el Gobierno de Japón anunció que ha decidido empezar a descargar al océano grandes cantidades de agua radiactiva que ha estado almacenada en la planta nuclear de Fukushima (LA Times, 2021).
} 


\section{Delimitando el escenario del conflicto jurídico: la Naturaleza en los tribunales}

En Ecuador, el pacto social renovado por el pueblo en el año 2008, incorporó a sus valores y metas constitucionales la decisión de construir una "nueva forma de convivencia ciudadana, en diversidad y armonía con la Naturaleza, para alcanzar el buen vivir, el sumak kawsay" (Constitución del Ecuador, 2008). Es así que el pueblo, a través del poder constituyente, amalgamó los derechos ambientales que ya existían desde tiempo atrás, con los emergentes derechos de la Naturaleza, dentro de un régimen de desarrollo que se modela sobre el extractivismo y el bienestar general.

A pesar de la regulación de los sistemas de protección a los derechos humanos ambientales y los derechos de la Naturaleza, la contaminación, el cambio climático, la pérdida de bosques, las especies en peligro de extinción, entre tantas otras, siguen siendo noticia en los periódicos del día domingo, porque la expedición de una regla no cambia la realidad ipso facto. Solo cuando se tiene la oportunidad de realizar aquellos "viajes a lo salvaje", a los que hace alusión Cormac Cullinan (2019), se perciben los problemas de la Naturaleza que nos dejan desconcertados por unos minutos, pero dejamos que la vida y el caos continúen.

En el campo de la justicia, y del litigio en particular, la cuestión constante es: ¿Qué es lo que busca una persona cuando decide someterse a un juicio? Para unos, la respuesta es utilitarista y dirán que lo que buscan es ganar el proceso, sin importar los medios que se usen para lograrlo, mientras que, otros, los más idealistas, buscarán seguramente, con un tinte axiológico: la justicia.

Sin embargo, en los casos en los que se ventilan derechos de otro sujeto que además es no-humano, o cuando la pretensión sobre la cual se basa el objeto de la controversia es la reivindicación del derecho a vivir en un ambiente sano, el actor del proceso pretende defender intereses que comparte con una colectividad difusa sobre el correcto funcionamiento de los sistemas ambientales (Martín Mateo, 1998).

En Ecuador, es posible instaurar procesos judiciales tanto para exigir la tutela efectiva de los derechos ambientales, como de los derechos de la Naturaleza, estos últimos a partir de la subjetivación de la Naturaleza en la Constitución expedida en el año 2008, en cuyo artículo 10 se señala que: “[...] La Naturaleza será sujeto de aquellos derechos que le reconozca la Constitución”, mientras que la judicialización de los derechos ambientales tiene una data anterior.

Si bien el denominador común de los juicios por derechos humanos ambientales y los instaurados para exigir los derechos de la Naturaleza es la concurrencia del ambiente al proceso -el cual sin duda debe protegerse -, el carácter de bienes colectivos o de derechos sui generis dificulta su exigibilidad y la tutela judicial efectiva, en tanto el sistema judicial no está diseñado para tutelar abstractamente el cumplimiento de las reglas, sino para sancionar el quebrantamiento del orden jurídico formal, o, en un ámbito más principialista, el orden social establecido.

En un proceso judicial que verse sobre derechos de la Naturaleza, el juzgador está obligado a abandonar la racionalidad económica instrumental en la que se ha fundado el modelo civilizatorio de la modernidad, por la racionalidad ambiental (Leff, 2000, p. 16), para finalmente conceder la razón a una de las partes procesales.

La legislación ecuatoriana, prevé diferentes vías para tutelar los derechos de la Naturaleza, los derechos ambientales humanos, los daños ambientales y los daños patrimoniales derivados de la presencia de un dańo ambiental, pero en todas estas, el juzgador está llamado a identificar y determinar de forma clara y precisa el objeto de la controversia, a efecto de encausar el litigio hacia su resolución, y de evitar incurrir en alguno de los vicios 
de las resoluciones judiciales. ${ }^{5}$ Sin embargo, lo que parecería ser un ejercicio lógico sencillo para el juzgador, se envuelve de complejidad cuando la litis pende atada a cuestiones técnicas especializadas e incluso a autorizaciones o licencias administrativas y a la posición ontológica que ha de asumir el juzgador.

\section{Exigibilidad de los derechos de la Naturaleza sin depender de los ambientales}

En cuanto a los aspectos de protección jurídica de los derechos de la Naturaleza específicamente, la interrogante que surge es: ¿Con qué criterios enfrenta un juez un proceso en el que la Naturaleza es sujeto y parte procesal al mismo tiempo?

El espacio utópico al que han sido sometidos los derechos de la Naturaleza, desde una perspectiva pesimista de la doctrina jurídica constitucional, propone la idea de que si bien pueden ser aspiraciones deseables para implementar un cambio de paradigma, en realidad se trata de prerrogativas o derechos irrealizables, pues al parecer, no superan las condiciones del racionalismo platónico y kantiano basado en la razón humana bajo la visión antropocéntrica: sin ser humano no hay razón, dignidad, ni derechos que reconocer o respetar.

En el marco del Derecho Ambiental, autores como Mario Peña Chacón y Ricardo Crespo, abogan por la tutela del ambiente a través del fortalecimiento de las instituciones propias de esta disciplina, o de la ecologización del Derecho Ambiental. Crespo, señala que es el Derecho Ambiental el que se ha diseñado para hacer respetar los límites biofísicos de los ecosistemas, sobre todo como Derecho Ambiental Administrativo, el cual es un Derecho ecologizado por influencia del reconocimiento de derechos a la Naturaleza (2019, pp. 136-137).

Lo expuesto por el autor está irradiado por el contenido de los instrumentos internacionales que ponen en vigencia principios ambientales que se quedan en el soft law y por el discurso ambiental promovido por la Organización de las Naciones Unidas, que supone que la aplicación y el robustecimiento de las leyes y la adopción de medidas en materia ambiental posibilita la protección de los derechos humanos y las libertades fundamentales.

Esta línea teórica, tiene la valía de reconocer implícitamente la inefectividad del Derecho Ambiental para lograr el objetivo de solventar la degradación ambiental, pero su propuesta apunta a la reconstitución del derecho positivo ambiental a partir de su tecnificación y raigambre científico, más sistémico en cuanto a la estructuración institucional de la gestión ambiental y más democrático y participativo (Peña Chacón, 2016, pp. 13-20), en dirección hacia el robustecimiento del conservacionismo, dejando de lado que este se fundamenta en una interpretación antropocéntrica de la Naturaleza (Bender, 2003, p. 72) y que los instrumentos de gestión ambiental fueron la respuesta que emergió del propio modelo económico extractivista, para alivianar la resistencia social por efectos de la crisis ambiental, a la vez que mantener el statu quo.

Quienes abogan por los derechos de la Naturaleza, consideran que al haberla reconocido como un sujeto se trastoca los presupuestos teóricos antropocentristas, (Narváez y Narváez, 2012, p. 176) y parten de los valores intrínsecos e inherentes al ecosistema, a los procesos ecológicos o vitales -como les denomina la Constitución ecuatoriana- y al equilibrio ecológico, que son "independientes de los valores otorgados por los seres humanos" (Gudynas, 2016, p.47) (Ferry, 1992, 32); y consideran que para que un ente sea reconocido como titular de derechos legales, debe tener un valor y una dignidad reconocidos por la Ley como derecho propio, además de cumplir tres criterios: a) que la cosa pueda interponer acciones legales en nombre propio; b) que la cosa misma sea afectada del daño que se le cause; y, c) que cualquier

\footnotetext{
${ }^{5}$ Los vicios de las resoluciones judiciales, a saber, son: Infrapetita, dejar de resolver pretensiones requeridas; extrapetita, resolver cuestiones distintas a las pretendidas; ultrapetita, resolver más allá de lo que se pretendió.
} 
compensación judicial que se produzca sea en beneficio de la cosa misma, cuyo aporte fue una de las primeras entradas jurídicas al reconocimiento de los derechos de la Naturaleza (Stone, 2009, pp.151-153).

De lo expuesto, se deriva que existen temas de orden filosófico y teórico que se transfieren a los procesos judiciales que versan sobre derechos de la naturaleza, porque el juzgador ha de visualizar el conflicto cuestionando el imperio de una racionalidad cosificadora y objetivadora, la mercantilización de la naturaleza y la economización del mundo (Leff, 2000, pp. 170-173).

\subsection{Variables a considerar por el juzgador}

Las consideraciones de orden teórico y jurídico, desarraigadas del enfoque antropocéntrico de tutela ambiental que se han expuesto, generan distancias y complicaciones entre el reconocimiento de los derechos de la Naturaleza y su ejercicio; la ausencia de contenidos sobre qué significan estos derechos; la vaguedad semántica de reconocerla como "sujeto de protección"; y, la dependencia al sendero antropocéntrico, son los límites epistémicos más fuertes a los que tienen que enfrentarse estos derechos y los juzgadores. Los investigadores sugieren a los operadores de justicia considerar las siguientes variables en la argumentación de sus sentencias.

\subsubsection{Primera variable: el "todo"}

Desde una postura filosófica naturista, que jurídicamente encontró en los derechos de la Naturaleza una institucionalidad que quiebra la visión antropocéntrica de la tutela del ambiente, se pretende erigir un modelo de protección basado en la comprensión del ser humano como parte constitutiva de un "todo", que se compone de elementos de igual valía para la existencia del equilibrio ecológico, que están regulados por leyes naturales que trascienden a aquellas de orden jurídico carentes de racionalidad ambiental. Al respecto, Sagot (2020) señala que, si bien los derechos humanos ambientales son vitales para un disfrute de la dignidad que como colectivo tenemos, el velar por ese bienestar, implica una situación utilitarista que conlleva a maximizar a los humanos como el centro de atención, y no tan solo como una parte de un gran ecosistema.

En la misma línea, De Sousa Santos afirma que "la concepción de la Naturaleza como parte integral de la sociedad, y no como algo separado de ella, implicaría una profunda transformación de las relaciones sociales y políticas. Entrañaría una refundación del Estado moderno. Eso fue justamente lo que intentaron hacer las constituciones de Ecuador de 2008 y de Bolivia de 2009” (2014, p. 56). Esta sería la primera variable a considerar por los operadores de justicia en los casos en los que se ventilen los derechos de la Naturaleza, pero no la única.

\subsubsection{Segunda variable: la comprensión de la razón humana no es la única racionalidad posible}

El saber ambiental y la racionalidad ambiental que envuelve a los derechos de la Naturaleza, no se configuran en un sentido común fundado en el reconocimiento ideológico de lo consabido, sino en la construcción de sentidos colectivos e identidades compartidas que constituyen significaciones culturales diversas en la perspectiva de pensar lo que aún no es. La complejidad ambiental configura una globalidad alternativa, como un mosaico de diferencias, como confluencia y convivencia de mundos de vida en permanente proceso de hibridación y diferenciación (Leff, 2000, p. 50). 
En este sentido, si se asume que no se puede entender nada por fuera de la Naturaleza, y que el ser humano es una parte y no el centro de todo, la razón humana no sería un elemento que permitiese elegir qué seres son protegibles o cuáles no, sino que la única forma sustentable de coexistencia sería tutelar el equilibrio ecológico en su conjunto, lo que propone el reconocimiento de derechos y límites a los potenciales excesos realizados contra la Naturaleza, que también trae efectos favorables a los seres humanos como parte de ella, aunque ese no sea su contenido esencial.

\subsubsection{Tercera variable: los casos peculiares}

Más allá de las características de los casos fáciles o difíciles, los jueces se enfrentan a atender casos peculiares, en los que la víctima de agresiones es "La Naturaleza", que además, es quien plantea un problema jurídico y requiere una respuesta; por tanto, las instituciones jurídicas generadas por el Derecho que resultarían usuales para atender estos casos peculiares, se desvanecen frente a la vista del juez y el auditorio, quienes ahora desprovistos de los principios pro-hommine o pro libertis, y la tan recurrente dignidad humana, más allá de la obnubilación que trae el impacto de atender un caso sobre la vida, sobre su importancia para la existencia de la humanidad y de todo su entorno, da la sensación de que las dimensiones jurídicas formalistas, positivistas o post-positivistas, se resisten a salir del estrecho estrado de la sala de juzgamiento y las reglas contenidas en extensos códigos, que a lo largo del tiempo han sometido al ser humano jurídicamente hasta el mínimo detalle, más no a la Naturaleza y el principio pro-natura, lo que no permite que el juzgador visibilice la dimensión e importancia de la protección de sus derechos.

¿A qué fuentes recurre un juez que piensa que todo el Derecho se reduce a la Ley? Ahora la Ley está subordinada a la norma supraordenada, que también es Ley, la cual incorpora a otras fuentes del Derecho y obliga a un ejercicio hermenéutico que incluye al bloque de constitucionalidad.

Como máximo ejercicio de transformación en el Derecho, algunos jueces arriesgados habrían de recurrir a la dignidad del ser humano como un ejercicio de aplicación de principios, pero actualmente están constreñidos a construir una respuesta epistémica que cambie el paradigma jurídico; lo otro es aferrarse a la Ley y negar el pedido.

Otros jueces, los positivistas más audaces, harán uso de la discrecionalidad y realizarán una hibridación entre el positivismo y la aplicación análoga de los derechos más cercanos a los de la Naturaleza, como son los derechos ambientales. Esto, connota la dependencia del sendero; es decir, a una institucionalidad y racionalidad arraigadas a las instituciones jurídicas que se conocen y que bloquean la posibilidad de asumir alternativas.

En cuanto a la práctica judicial, en Ecuador, los derechos de la Naturaleza tienen un reconocimiento constitucional. Sin embargo, usar la técnica de la analogía entre el Derecho Ambiental y los derechos de la Naturaleza, provoca una superposición de carácter antropocéntrico que somete a los derechos de la Naturaleza al angosto espacio jurídico del positivismo formalista de los derechos ambientales. Es una confusión que resta vida propia a los derechos de la Naturaleza, afectando su esencia y protección.

La concurrencia de categorías y criterios técnicos que revisten a los derechos ambientales, en los casos en los que el objeto de la controversia son los derechos de la Naturaleza, es una versión positivista que vacía de contenidos sustanciales a estos últimos. Si bien los derechos constitucionales requieren para su protección de un ejercicio hermenéutico de textura abierta para dotarlos de significados interpretativos, el formalismo migra a espacios más cómodos, que conllevan el rechazo a la protección de los principios del debido 
proceso o la libertad, ejercicios que son insuficientes si no se consideran en el contexto. El constitucionalismo, considerado como teoría, como ideología, y como método, posibilita ese procedimiento.

\subsubsection{Cuarta variable: El bien jurídico protegido}

Ahora bien, los derechos de la Naturaleza requieren de un ejercicio epistémico, ontológico y axiológico correspondientes con el equilibrio ecológico, la comunidad global, y la resiliencia vinculada a la autocomposición de la recreación de la vida en la Naturaleza. En ese sentido, cabe identificar criterios distintivos para discernir cuándo un juez actúa desde el enfoque antropocéntrico o desde una visión biocéntrica o ecocéntrica, como se explica en la siguiente tabla:

\begin{tabular}{|c|c|c|}
\hline Categoría & Derechos de la Naturaleza & Derecho a vivir en un ambiente sano \\
\hline Parte procesal & La Naturaleza como sujeto & Ser humano \\
\hline $\begin{array}{c}\text { Bien jurídico } \\
\text { tutelado }\end{array}$ & $\begin{array}{c}\text { Ecosistemas y procesos ecológicos (vitales), } \\
\text { como un todo }\end{array}$ & $\begin{array}{c}\text { Ambiente sin riesgos, limpio, saludable } \\
\text { y sostenible }\end{array}$ \\
\hline Objetivo & Equilibrio ecológico & Calidad de vida \\
\hline $\begin{array}{c}\text { Cuestiones } \\
\text { conexas }\end{array}$ & $\begin{array}{c}\text { Integralidad de la vida, equilibrio ecológico y } \\
\text { resiliencia }\end{array}$ & $\begin{array}{c}\text { Libertad, igualdad, debido proceso y } \\
\text { seguridad jurídica }\end{array}$ \\
\hline Enfoque & Biocéntrico - Ecocéntrico & Antropocéntrico \\
\hline Garantía & Tutela del sujeto Naturaleza & Tutela del patrimonio natural del ser \\
humano
\end{tabular}

Figura 1. Diferencias entre los Derechos de la Naturaleza y los Derechos ambientales humanos. Elaboración propia.

No se ha de dejar por fuera que, tratándose de la tutela de los derechos de la Naturaleza, el juez debe considerar su valor de uso, esto es: a) la propuesta generacional de la existencia de los elementos y de la incertidumbre sobre las capacidades de supervivencia de las generaciones futuras, si no cuentan con los elementos naturales que se extinguen en el presente (Sánchez, 2019, p. 106); b) los valores hedónicos incuantificables que se conectan con la biocultura (Cristeche y Penna, 2008, pp. 26-28); c) los valores bioconexos que devienen de la interacción del ambiente con derechos humanos como la salud, la vida y la integridad (Corte Constitucional de Colombia, 2016); y, d) los valores ecológicos expresados por la diversidad de especies y elementos abióticos que cumplen un rol específico en la mantención del equilibrio ecológico (Gudynas, 2016, pp. 44-53). De estas perspectivas valorativas, las tres primeras atienden a un enfoque biocéntrico y solo la última a un enfoque ecocéntrico, como lo expone Ferry:

[...] el antiguo "contrato social" de los pensadores políticos debe ceder su lugar a un "contrato natural" en el cual el universo entero se volvería sujeto de derecho: ya no es al hombre considerado como centro del mundo al que hay que proteger en primer término de sí mismo, sino al cosmos como tal al que hay que defender de los hombres. El ecosistema -la biósferaaparece entonces investido de un valor intrínseco, por cierto, muy superior al de esa especie, a fin de cuentas, más bien dañina, que es la especie humana (1992, p. 32). 
A continuación, se presenta el análisis de la hipotética dependencia de los derechos de la Naturaleza a los derechos ambientales, así como el reto de sacarles del espacio utópico al que han sido sometidos y reconocer las buenas prácticas judiciales en el desarrollo autónomo de los derechos de la Naturaleza.

\section{Estudio de caso de los derechos de la Naturaleza en Ecuador}

Los derechos de la Naturaleza son asumidos en el Ecuador a partir de la existencia de conflictos que ponen en evidencia la contraposición de intereses de los actores sociales con capacidad de incidencia política, frente al derecho colectivo a vivir en un ambiente libre de contaminación, para redefinir la relación entre el ser humano y la Naturaleza como una nueva forma de convivencia ciudadana, en diversidad y armonía con la Naturaleza, para alcanzar el buen vivir o sumak kawsay, desde la perspectiva de la sostenibilidad (Preámbulo de la Constitución de la República del Ecuador del año 2008).

\subsection{El caso del Manglar Cayapas Mataje contra la empresa Marmeza}

El ecosistema donde se asienta la Reserva ecológica Cayapas - Mataje ha sido afectado por las operaciones de la empresa camaronera Marmeza, generando graves vulneraciones a los derechos de la Naturaleza, según lo refiere en su demanda el Director Provincial del Ministerio del Ambiente de Esmeraldas. Esta afirmación, parte de la comprensión de ecosistemas como sistemas vivos del planeta que incorporan la energía del sol, recogen y reciclan los elementos nutritivos y organizan cadenas alimenticias que pueden manifestarse en una multiplicidad de formas.

Como se verá en el siguiente análisis, la visión que guía al juzgador es que la tutela de derechos se circunscribe a la zona geográfica ecológica protegida, reduciendo el análisis a los criterios técnicos derivados del Derecho Ambiental, desnaturalizando así los contenidos esenciales y alcances de los derechos de la Naturaleza.

\subsection{Hechos del caso}

En el año 2010, la Dirección Provincial del Ministerio del Ambiente de Esmeraldas emitió un acto administrativo por el cual disponía el desalojo de la actividad acuícola desarrollada por la compañía Marmeza S.A., del espacio en el que la actividad acuícola de la empresa se superponía con la Reserva Ecológica Mataje Cayapas (REMACA), porque existían evidencias de que la empresa había extendido el espacio de ocupación de su actividad acuícola más allá del área concesionada y dentro de la reserva.

Marmeza S.A., propuso una acción de protección contra la Dirección Provincial del Ministerio del Ambiente de Esmeraldas, señalando que se le había vulnerado el derecho de propiedad, al ordenar el desalojo del inmueble sobre el cual tiene derecho a acceder. La empresa indicó que, el 11 de agosto de 1993 y 10 de febrero de 1994, pagó al Estado ecuatoriano por el derecho al uso y ocupación de las playas y bahías de la Armada del Ecuador, Capitanía del Puerto de San Lorenzo y que estaba habilitada a realizar actividades productivas en este territorio, ocupando 26.45 hectáreas de un total de 36.61 hectáreas, razón por la exige la tutela de sus derechos a la seguridad jurídica y la propiedad privada, considerando que la instalación y operación de la camaronera empezó con anterioridad a la expedición de la declaratoria de la Reserva Ecológica Mataje Cayapas (REMACA), reconocida en el Decreto Ejecutivo No. 052, del ańo 2002, y mucho antes del reconocimiento constitucional de los derechos de la Naturaleza en el ańo 2008. 
Al respecto, el juez de primer nivel acepta la acción de protección considerando que las actividades de la empresa fueron autorizadas por el Estado antes de la declaratoria de la reserva ecológica y en un sentido similar se pronuncia la Sala de la Corte Provincial de Justicia de Esmeraldas, la cual se decanta por rechazar la apelación a la sentencia de la acción de protección No. 281-2011, porque considera que el acto administrativo violenta los derechos de propiedad y del trabajo de Marmeza, sin dedicar ni un solo razonamiento al análisis del impacto de las actividades antrópicas en los manglares que se encuentran protegidos por la declaratoria de la reserva ecológica y que han sido reconocidos como un ecosistema frágil en el artículo 406 de la Constitución de la República, con lo que excluyó la afectación a los derechos de la Naturaleza.

Finalmente, el Ministerio del Ambiente presentó una acción extraordinaria de protección, aduciendo que la Corte Provincial de Esmeraldas incurrió en una afectación al derecho al debido proceso en cuanto a la garantía de la motivación, porque el argumento de la resolución judicial no ha considerado todos los derechos que han concurrido en el conflicto y deja de pronunciarse sobre las razones por las que el juzgador optó por preponderar los derechos a la propiedad y seguridad jurídica de Marmeza sobre los derechos de la Naturaleza.

Con estos elementos, el 20 de mayo de 2015, la Corte Constitucional del Ecuador conoció el caso y revisó el derecho a la motivación de la sentencia accionada y la interrelación que tiene este derecho con los derechos de la Naturaleza.

\subsection{El derecho a la motivación en las decisiones judiciales que tratan sobre los derechos de la Naturaleza}

En la sentencia de acción extraordinaria de protección No. 166-15-SEP-CC, la Corte Constitucional verificó el objeto y finalidad de la garantía jurisdiccional extraordinaria de protección, y decidió resolver el siguiente problema jurídico: ¿La sentencia dictada por la Sala Única de la Corte Provincial de Esmeraldas, vulnera o no, el derecho al debido proceso en la garantía de la motivación de las resoluciones de los poderes públicos? Para ello, procedió a identificar el contenido del derecho a la defensa y a la motivación reconocidos en el artículo 76 de la Constitución, indicando que las personas tienen derecho a varias garantías procesales básicas dentro de las cuales consta la obligación de las autoridades públicas de emitir resoluciones motivadas; es decir, que las decisiones judiciales cuenten con certeza jurídica, principalmente para quienes son los directamente afectados por las decisiones de los poderes judiciales, en tanto este derecho exige que las decisiones estén debidamente justificadas.

El derecho a la motivación no es una mera declaración de normas o principios en una sentencia, sino que exige que en sus partes: expositiva, considerativa y resolutiva, deba visualizarse el resultado de la aplicación del derecho en relación a los hechos, de la lógica y argumentación jurídica.

En el caso, la Corte Constitucional de Ecuador refiere que desarrolló un test de motivación para verificar si una sentencia vulnera o no este derecho, y cita a la sentencia No. 227-12-SEP-CC, estableciendo como parámetro de análisis la razonabilidad, la lógica, y la comprensibilidad. Aun cuando no es parte de este artículo cuestionar la validez del test, este presentó varias falencias y simplificaciones realizadas por el órgano constitucional, como el hecho de que la razonabilidad se vuelve un requisito formal que verifica si un fallo es válido cuando se dicta con base en normas constitucionales y legales. Es lógico cuando las conclusiones se desprenden de las premisas, y la compresibilidad se basa en las exigencias del uso de un lenguaje común que esté al alcance de la comunidad en general. Ciertamente, son parámetros muy amplios que afectan a la seguridad del análisis. 
A partir de estos elementos, la Corte encontró que la falta de conocimiento de los derechos de la Naturaleza por parte de los jueces causaba una afectación al principio de motivación, al respecto, en la parte pertinente la Corte señaló que:

[...] los derechos de la Naturaleza constituyen una de las innovaciones más interesantes y relevantes de la constitución actual, pues se aleja de la concepción tradicional "Naturalezaobjeto que considera a la Naturaleza como propiedad y enfoca su protección exclusivamente a través del derecho a gozar de un ambiente sano, para dar paso a una noción que reconoce los derechos propios a favor de la Naturaleza. La novedad consiste entonces en un cambio de paradigma sobre la base del cual, la Naturaleza en tanto ser vivo, es considerada un sujeto titular de derechos (Corte Constitucional, 2015, p.9)

Este argumento distingue la diferencia entre el derecho a vivir en un ambiente sano (antropocéntrico) y los derechos de la Naturaleza (biocéntricos o ecocéntricos, según la convergencia o no de derechos humanos bioconexos); sin embargo, a renglón seguido, fusiona al sujeto-objeto en una sola categoría, cuando argumenta que:

En ese sentido, es importante resaltar que la Constitución de la República consagra una doble dimensionalidad sobre la Naturaleza y el ambiente en general, a concebirla no solo bajo el tradicional paradigma de objeto de derecho, sino también como sujeto, independiente y con derechos específicos propios (Corte Constitucional, 2015, p.10)

Luego, el órgano constitucional realizó un extenso argumento de cómo deben comprenderse los derechos de la Naturaleza o Pachamama, en el contexto de la Constitución, en una dimensión de los valores reconocidos en el preámbulo y el contenido propio del artículo 72 de la Constitución, que señala que "la Naturaleza tiene derecho a la restauración", adoptando las medidas adecuadas para mitigar las consecuencias nocivas. De ahí que las obligaciones del Estado sean garantizar el efectivo goce de estos derechos, constituyendo a los jueces en quienes deben velar por su protección.

Así la cuestión, en virtud de la cual la Naturaleza y el ambiente confluyen en una zona gris, la Corte Constitucional observó que la sentencia de la Corte Provincial de Esmeraldas se enfocó en un primer momento en los derechos a la propiedad y el trabajo que generaba Marmeza, desplazando así el contenido de los derechos de la Naturaleza.

La Corte Constitucional hace dos señalamientos al respecto:

"[...] la ausencia de análisis, e incluso de enunciación, respecto a los derechos que la Carta Magna consagra a favor de la naturaleza, dentro de un proceso que involucra esencialmente la protección y conservación de una reserva ecológica, revela una absoluta negación del reconocimiento de esta zona como área protegida y de forma simultánea, una negación del reconocimiento del derecho de las personas a vivir en un ambiente sano y ecológicamente equilibrado" (Corte Constitucional, 2015, p.14).

"[...] al tratarse de una reserva ecológica, el lugar donde se encuentra ubicada la camaronera MARMEZA, representa un área natural patrimonio del Estado, cuya administración corresponde al Ministerio del Ambiente" (Corte Constitucional, 2015, p.15)

De lo expuesto se desprende que la Corte decidió hacer énfasis en una categoría ambiental y reduccionista de la protección de derechos de la Naturaleza, sometiendo a los actores a la voluntad del poder estatal y a límites ambientales devenidos de los mecanismos de 
conservación, como son el sistema nacional de áreas protegidas y las zonas declaradas como reserva ecológica, con lo cual, la protección de los derechos de la Naturaleza quedó limitada a este espacio declarado bajo el imperio del Estado, ya que la potestad de determinar una zona ambiental protegida es competencia de la Autoridad Ambiental Nacional.

En cuanto al derecho a la motivación se evidencia otra contradicción. La Corte Constitucional consideró que no hay relación entre las premisas y las conclusiones, lo que le permitió afirmar que la decisión no se encontraba debidamente motivada en el parámetro de la lógica. Sin embargo, sostuvo que la decisión es diáfana y que cumplió con el parámetro de compresibilidad, lo que en realidad sorprende, porque si no es lógica resulta imposible que el texto sea comprensible, lo que deja aún más dudas que certezas.

Siendo fiel con su práctica de devolución de casos, para que las instancias judiciales inferiores elaboren nuevas sentencias, la Corte Constitucional dispuso a la Sala de la Corte Provincial de Esmeraldas que realice un nuevo fallo a partir de estos confusos parámetros de la motivación, los derechos ambientales y los derechos de la Naturaleza. A la presente fecha, la sentencia dispuesta aún no ha sido expedida.

\subsection{Análisis de los argumentos desarrollados de los derechos de la Naturaleza y los ambientales}

Si bien, la Corte Constitucional aceptó la acción interpuesta por el Ministerio del Ambiente, y en razón de sus argumentos resolvió declarar la vulneración del derecho constitucional al debido proceso, específicamente a la motivación, por la omisión en la que incurrió la Corte Provincial al no abordar los derechos de la Naturaleza en su fallo, no es menos cierto que el razonamiento de los operadores de justicia constitucional se limitó a recurrir a instituciones jurídicas existentes en el ordenamiento jurídico nacional en el marco del preservacionismo propio del Derecho Ambiental, que no apuntalan a nutrir el contenido esencial de los derechos de la Naturaleza, cuyos fundamentos ya han quedado expuestos, y no son los mismos sobre los que se erige "el derecho a vivir en un ambiente sano".

Más allá del resultado positivo del caso en favor de la Naturaleza, a modo de una falacia de petición de principio, es clara la visión antropocéntrica que reviste la decisión de los jueces constitucionales, en tanto su argumentación se ancla a criterios técnicos derivados del conservacionismo del Derecho Ambiental, que tienden a la exclusión de espacios geográficos determinados de aquellos habilitados para que el ser humano ejerza actividades económicas, cuyo efecto es supeditar la vigencia de los derechos de la Naturaleza a la existencia o no de un área protegida.

A partir de aquí se pueden identificar normas constitucionales que regulan los temas de la Naturaleza desde dos perspectivas: i) las que la reconocen como sujeto de derechos (perspectiva biocéntrica o ecocéntrica); y, ii) como derechos de las personas y colectividades, constituyéndose en objetivo y límite para la actividad estatal (perspectiva antropocéntrica, de derechos humanos o ambientalistas).

Como se indica, la Corte desarrolla elementos que favorecen a la Naturaleza como sujeto de derechos autónomos, de la misma forma que desarrolla argumentos que plantean una dependencia de la Naturaleza con el derecho humano y constitucional al ambiente sano, de lo que se colige un gran desgaste retórico que inició con sendos párrafos que declararon la revolución del Derecho, propios de un cambio de paradigma, con la euforia de los nuevos Derechos, y terminó con la resignación que confirma el status quo del Derecho Ambiental por sobre los derechos de la Naturaleza, al declarar que nada ha cambiado; una vuelta argumentativa engañosa que define que la propiedad del Manglar pasa de las manos privadas 
de Marmeza a manos del Estado, dando como resultado que el derecho de propiedad sea el que más se garantizó.

Del análisis del caso, cuyo punto final favoreció a la Naturaleza, se desprende que la Corte no fundamentó la sentencia en la efectiva vigencia de tales derechos, ni nutrió su contenido, por lo que resulta necesario librar a los derechos de la Naturaleza de la sombra del derecho de la propiedad, del trabajo y de las categorías devenidas del Derecho Ambiental. Está claro que, los entramados jurídicos tradicionales, positivistas y formalistas de una sentencia no le hacen justicia a la voluntad del constituyente, que es la voluntad del pueblo. Genera la impresión de que cualquier cambio en el Derecho tiende a diluirse por tradición y ausencia de contenidos, como ha ocurrido en el presente caso.

\section{Conclusiones}

La Naturaleza como sujeto, tiene derechos autónomos que no dependen de la dignidad que proclaman los derechos humanos, por lo que resultó indispensable tratar en el presente artículo las semejanzas y diferencias entre los derechos humanos ambientales y derechos de la Naturaleza, con el objeto de evitar superposiciones que anulan su contenido y eficacia.

El reconocimiento constitucional de los derechos de la Naturaleza en Ecuador ocurrió en el año 2008. Esto no fue producto de un avance del Derecho Ambiental, todo lo contrario, respondió al evidente fracaso de esta rama del Derecho para detener y contrarrestar la crisis ambiental, por lo que el constituyente ecuatoriano decidió abordar la relación del ser humano como parte de la Naturaleza, irradiada por la cosmovisión de los pueblos indígenas, a fin de legitimar un medio político y jurídico que le reconozca como un sujeto de derechos y evitar los abusos que esta sufre por parte del Estado, las empresas, y los seres humanos. No obstante, se examina que el pensamiento no hegémonico occidental también propone otros fundamentos que aúnan por la subjetivación de la Naturaleza, los cuales están a disposición de los operadores de justicia para la construcción de argumentos que se constituyen en estándares jurisprudenciales.

Se trata de un sujeto jurídico nuevo, que permite cambiar el enfoque de dominación que ha tenido el ser humano sobre la Naturaleza, la cual ha sido tratada como una cosa, propiedad, un bien dependiente del ser humano o una utopía constitucional, pasando a ser un sujeto vivo del cual dependen la vida y el equilibrio ecológico, por lo que merecen ser protegidos.

Desde un punto de vista externo al Derecho, a la Naturaleza como sujeto de derechos se le ha ridiculizado y se ha intentado desconfigurar el propósito de su existencia; mientras que, desde un punto de vista interno del Derecho, se le ha desconocido su autonomía como sujeto de derechos, se le ha tratado como una cosa u objeto de propiedad y se la ha analizado como una parte del Derecho Ambiental dependiente del ser humano o del Estado, aspecto en el que hace énfasis el presente artículo.

La Corte Constitucional del Ecuador, luego de 12 años de la vigencia de la Constitución ecuatoriana (2008), por ende, del reconocimiento de la Naturaleza como sujeto de derechos, ha seleccionado varios casos sobre estos derechos, sin que hasta el momento en el que se ha escrito este artículo se haya desarrollado ningún precedente jurisprudencial obligatorio, por lo que ha resultado complejo elegir casos para este estudio, siendo la única acción que cuenta con un pronunciamiento del Alto Tribunal el caso Marmeza, planteado como una acción extraordinaria de protección, garantía diseñada para la protección de derechos ante casos en los cuales los jueces vulneran derechos constitucionales de las partes 
sometidas a un juicio y decisión. Más allá de esto, el caso permite analizar las consideraciones que han realizado los jueces sobre los derechos de la Naturaleza.

En ese sentido, el artículo aporta a identificar las diferencias entre el derecho humano y constitucional a un ambiente sano y los derechos de la Naturaleza, incluyendo los fundamentos de estos últimos. Del análisis realizado del caso Marmeza, en el cual se pretende la tutela de los Manglares Mataje Cayapas, se han cuestionado los argumentos de los jueces de primera y segunda instancia, así como los de la Corte Constitucional, concluyendo que en los juzgadores no solo existe un anclaje a la visión antropocéntrica de tales derechos, sino que se los ha reducido a la estrechez del insuficiente Derecho Ambiental y de derechos como la propiedad y la seguridad jurídica. Si bien, de un lado se reconocen los esfuerzos argumentativos de la Corte que proclaman el cambio de paradigma en el reconocimiento de la Naturaleza como sujeto de derechos; de otro lado, es evidente que se ha dado un paso atrás al plantear la dependencia implícita de los derechos de la Naturaleza con la propiedad y las instituciones ortodoxas del Derecho Ambiental.

Como bien señala George Orwell en Rebelión en la granja, toda revolución termina en el mismo lugar donde empieza, pues en el pasaje en el que los animales declaran: "dos patas no, cuatro patas sî" (2004, p. 116), rechazando a los humanos, es sorprendente cuando el cerdo Napoleón, líder de la rebelión, se adiestra para caminar en dos patas, reunirse y hacer negocios con los humanos, toda la distinción en la que se basaba la rebelión en la granja se habría disuelto como sal en el agua, del mismo modo como ocurre en esta sentencia con los derechos de la Naturaleza que iniciaron con la declaración del cambio de paradigma de los derechos biocéntricos nacidos en la Pacha Mama distintos al ser humano, afirmación que podría ser falaz, ya que se sometería los derechos de la Naturaleza a la dependencia y dominio de los derechos ambientales y de la propiedad, procurando reducir su ámbito de protección a una mínima expresión como son los límites de la zona ecológica bajo el derecho de "propiedad" del Estado, como cualquier otro objeto y no como sujeto de derechos.

Finalmente, el presente estudio es crítico, pero no por ello es pesimista, sino que, a partir de las falencias argumentativas y confusión de los derechos de la Naturaleza con los derechos ambientales y constitucionales eminentemente humanos, se propone una separación epistémica en favor de los primeros y una forma de cambiar el tratamiento de estos casos con el fin de fortalecer el proceso argumentativo la Naturaleza como un sujeto que defiende sus derechos.

\section{Referencias bibliográficas}

Bender, F. (2003). The culture of extinction: Toward a philosophy of Deep Ecology. Amherst: Rowman \& Littlefield Publishers / Humanities Press.

Crespo, R. (2019). El dilema jurídico respecto a los derechos de la Naturaleza. En M. Peña Chacón (Ed.), Derecho Ambiental del siglo XXI (págs. 133-172). San José: ISOLMA.

Cristeche, E., y Penna, J. (2008). Métodos de valoración económica de los servicios ambientales. Revista Estudios socioeconómicos de la sustentabilidad de los sistemas de producción y recursos naturales, 3, 5-53.

Cullinan, C. (2019). Derecho Salvaje. Quito: Huaponi/UASB Ecuador.

De Sousa Santos, B. (2014). Derechos humanos, democracia y desarrollo. Bogotá: Dejusticia.

Ferry, L. (1992). La ecología profunda. Revista Vuelta, 192, 31-43. 
González Márquez, J. (2003). La responsabilidad por el daño ambiental en América Latina. México: PNUMA

Gudynas, E. (2016). Derechos de la Naturaleza. Ética biocéntrica y politicas ambientales. Quito: Abya-Yala.

L.A. Times (2021). Japón verterá al mar agua almacenada en planta de Fukushima. 13/04/2021. https:/www.latimes.com/espanol/internacional/articulo/2021-04-13/japonvertera-al-mar-agua-almacenada-en-planta-de-fukushima\#: - :text=El\%20gobierno $\% 20 \mathrm{de} \% 20 \mathrm{Jap} \% \mathrm{C} 3 \% \mathrm{~B} 3 \mathrm{n} \% 20$ anunci\%C3\%B3,habitantes\%20y\%20vecinos $\% 20 \mathrm{del} \% 20 \mathrm{pa} \% \mathrm{C} 3 \%$ ADs.

Leff, E. (2000). Pensar la complejidad ambiental. En E. Leff (Coord.), La complejidad ambiental (págs. 7-53). México: Siglo XXI editores.

Leff, E. (2002). Saber ambiental. México: Siglo XXI editores.

Martín Mateo, R. (1998). Manual de Derecho Ambiental. Madrid: Trivium.

Morato, J. y Franca, F. (2019) Derechos de la Naturalez: Fundamentos y protección por el Estado ecológico de Derecho en América Latina. En M. Peña Chacón (Ed.), Derecho Ambiental del siglo XXI (pp.. 93-132). San José: ISOLMA.

Narváez, I. Narváez, M. J. (2012). Derecho Ambiental en clave neoconstitucional (enfoque político). Quito: FLACSO Ecuador.

Orwell, George (2004). Rebelión en la granja. Madrid: Destino.

Peña Chacon, M. (2016). Derecho Ambiental efectivo. San José: Universidad de Costa Rica.

Rodríguez, G. y Vargas-Chávez, I. (2019) Avances del Derecho Constitucional colombiano: Una mirada desde la interpretación jurisprudencial. En M. Peña Chacón (Ed.), Derecho Ambiental del siglo XXI (págs. 213-244). San José: ISOLMA.

Sagot, A. (Julio de 2020). La nueva otredad. Los ecositemas como sujetos reconocidos jurídicamente. Revista Iberoamericana de Derecho Ambiental y Recursos Naturales, 36.

Sánchez, J. (2019). Recursos naturales, medio ambiente y sostenibilidad. Santiago: CEPAL.

Stone, C. (2009). ¿¿os árboles deberían tener legitimidad procesal? Hacia un reconocimiento de los derechos legales de los objetos naturales. En C. Crawford (Ed.), Derecho Ambiental y justicia social. Bogotá: Siglo del hombre editores.

\section{Jurisprudencia}

Corte Constitucional de Colombia (2016) Acción de tutela interpuesta por el Centro de Estudios para la Justicia Social "Tierra Digna" y otros contra la Presidencia de la República de Colombia y otros. No. T-622. Sentencia de 10 de noviembre de 2016.

Corte Constitucional del Ecuador (2015) Acción extraordinaria de protección interpuesta por el Director provincial del Ministerio del Ambiente de Esmeraldas. Caso No. 0507-12-EP. Sentencia No. 166-15-SEP-CC de 20 de mayo de 2015. 